\title{
Effect of Yoga on Depression and Somatic Symptoms of Women Labourers
}

\author{
Naorem Shyami Devi ${ }^{1}$, Dr. Naorem Jiteswori Devi ${ }^{2}$, Dr. Ashween Shashikant Bilagi ${ }^{3^{*}}$ \\ ${ }^{1}$ MSc Yoga, Distance Education, Svyasa University, Eknath Bhavan, Gavipuram Circle, K G Nagar, Bangalore.-560091, India \\ ${ }^{2} \mathrm{PhD}$, Research Officer, Bapu Nature Cure Hospital \& Yogashram, Mayur Vihar-I, Delhi-91, India \\ ${ }^{3}$ M.D, Asst. Professor, Svyasa University, Eknath bhavan, Gavipuram Circle, K G Nagar, Bangalore.-560091, India

\section{Corresponding Author} \\ Dr. Ashween Shashikant Bilagi \\ M.D., Asst. Professor, Svyasa University, Eknath bhavan, Gavipuram Circle, K G Nagar, Bangalore.-560091, India \\ Contact No: 9886666636 \\ E-mail: ayushashwin@gmail.com
}

\begin{abstract}
Yoga is one of the most effective and suitable tools to control various types of physical and psychological problems. The objectives of the study were to investigate the effect of yoga on depression and somatic symptoms on women labourers. Thirty five (35) women labours with ages ranging from 18 to 60 years after fulfillment of their inclusion and exclusion criteria had undergone yoga intervention program for 3 months. They were assessed on the 1st and the last day of the programme using BDI II and SASS questionnaires. There were significant reduction after yoga intervention in depression scores (BDI-II) (p<0.001) and in SASS Domain 1, 2,3 and $4(p<0.001)$. Regular practice of yoga can be a beneficial, cost effective and self-corrective practice for labour women's to retain the healthy mental health, further RCT's are required to support.
\end{abstract}

Keywords: Yoga, Depression, Somatic Symptoms, Women, Labourer

\section{Introduction}

Women form an integral part of the Indian workforce. According to the information provided by the office of Registrar General \& Census Commissioner of India, As per Census 2011, the total number of female workers in India is 149.8 million and female workers in rural and urban areas are 121.8 and 28.0 million respectively. Out of total 149.8 million female workers, 35.9 million females are working as cultivators and another 61.5 million are agricultural labourers. Of the remaining female workers, 8.5 million are in household Industry and 43.7 million are classified as other workers. The work participation rate for women in rural areas is 30.02 per cent as compared to 15.44 per cent in the urban areas[1]. Many characteristics of women's work activities have adverse consequences for their health and well-being. The Socio-Economic factors related health such as malnutrition, overburden of physical work, and lack of approach to available facilities reflect gender discrimination and related problems. For women, it made them more vulnerable to diseases and ill-health. The poor dietary intake due to heavy physical labour, performing all house- hold duties along with work outside the home leads to chronic energy deficiency and severe anemic condition. The status of women's health is largely reflected by female mortality and morbidly, disease burden, reproductive behaviors, nutrition, work environment, violence and its consequences on the health care system[2].

Hence, still there is not only a need to look at women's health and some of their social and physical environment and experiences to understand their status, but also to find the some measures to improve their health. Yoga can be one of therapy which can help them to achieve wellbeing of physical and mental health.
Yoga has been practiced in India over several centuries to promote positive health and well-being. It is considered to be a tool for both physical and mental development of an individual. It gives solace for the restless mind and can give great relief to the sick person. It has become quite necessary even for others to keep fit. Some use yoga for developing memory, intelligence and creativity. With growing scientific evidence, yoga is emerging as an important health behaviormodifying practice to achieve sound states of health, both at physical and mental levels. Several studies have demonstrated the beneficial effects of yoga on health behavior in many lifestyle-related somatic problems such as hypertension, bronchial asthma, diabetes including some psychiatric conditions such as anxiety neurosis and depressive illness etc[3]. Many studies conclude that yoga improved functioning of the mind. A study [4] showed that mindfulness meditation improved psychological wellbeing and reduced psychological symptoms of stress related problems, illness and anxiety. Gupta et al., [5] concluded that lifestyle modification based on yoga and stress management led to remarkable reduction in anxiety score within a period of ten days. Yogic breathing relieves post-traumatic stress disorder and depression[6].

Objectives: To study the effect of yoga on somatic symptoms and depression scores of women labourers.

\section{Materials and Methods}

Subjects: 35 women labourers with the mean of age $45 \pm$ 13.62 years, who agreed to participate in the study, were taken as subjects. 


\section{International Journal of Science and Research (IJSR) \\ ISSN (Online): 2319-7064}

Index Copernicus Value (2013): 6.14 | Impact Factor (2014): 5.611

\section{Inclusion Criteria:}

- Women labourers 18 to 60 years old.

\section{Exclusion criteria:}

- Substance abuse,

- Under treatment with psychotherapy / psychiatry

- Pregnancy and breast-feeding women

- Critical health implications

- Abdominal surgery less than six months

\section{Source of Subjects}

Subjects were residents of Kakching, Manipur.

\section{Place of study}

Community hall - known to all the subjects, who have undergone Yoga intervention (Kakching).

Ethical consideration: The study was approved by IRB of SVYASA University. A signed Informed consent was obtained from all the subjects who participated in the study.

\section{Design of the Study}

It is one group pre post design. The yoga group has undergone intervention program for the span of three months. Assessments were made before and after the three months program.

\section{Assessments}

Assessments were made on the group before and after three months of intervention. The following Psychological variables were assessed:

\section{Beck Depression Inventory (BDI-II)}

The Beck Depression Inventory (BDI) is a 21-item, selfreport questionnaire that assesses depressive symptoms experienced in the past two weeks. Scores range from 0 to 63 , with higher scores indicating higher levels of depressive symptoms [7]. The BDI-II is positively correlated with the Hamilton Depression Rating Scale with a Pearson $r$ of 0.71 , showing good agreement. The test was also shown to have a high one-week test-retest reliability (Pearson $r=0.93$ )[8].

\section{Scale for Assessment of Somatic Symptoms (SASS) [9].}

This scale contains 20 symptoms, each of which is rated on a 4-point scale $(0=$ absent to $3=$ severe $)$. SASS assesses 4 clusters of somatic symptoms: (a) pain related symptoms (e.g., headache, abdominal pain), (b) sensory somatic symptoms (e.g., tingling, palpitations), (c) non-specific symptoms (e.g., weakness of body, trembling) and (d) biological function related symptoms (e.g., lack of sleep, diarrhea).

\section{Intervention}

The intervention was given for 3 months. The 6 days in a week (one hour and 10 mins per day) schedule for yoga practices are detailed table 1 below.

Table 1: Daily Yoga Practice

\begin{tabular}{|l|c|}
\hline \multicolumn{1}{|c|}{ Name of Practice } & Duration \\
\hline Warming up (Sithilikaranavyayama) & $5 \mathrm{mins}$ \\
\hline Surya Namaskara & $15 \mathrm{mins}$ \\
\hline Relaxation Techniques (QRT)- in Savasana & $4 \mathrm{mins}$ \\
\hline $\begin{array}{l}\text { Asana: Ardha kati chakrasana, Ardha chakrasana, } \\
\text { Trikonasana, Vakrasana, Matsyasana, Viparita } \\
\text { karni, Bujangasana, Ustrasana. }\end{array}$ & $15 \mathrm{mins}$ \\
\hline Relaxation techniques (DRT)- in Savasana & $6 \mathrm{mins}$ \\
\hline Pranayama & $10 \mathrm{mins}$ \\
\hline Meditation & $15 \mathrm{mins}$ \\
\hline
\end{tabular}

Note: Out of the seven days, one day (every Saturday) to be devoted only to Kriya.

\section{Data Extraction and Analysis}

Data was extracted using standard procedures for all the variables. Psychological variables were scored as per standard scoring guidelines. Data was organized and tabulated for statistical analysis. Data was analyzed using statistical package SPSS software (Version 16.0). The data was normally distributed. Hence the effect of intervention was analyzed using Paired t-test.

\section{Result}

It was pre-post studies of the yoga group constituted of thirty five subjects. Pair t' test was done to compare within the group. There was significant reduction after yoga intervention in depression scores (BDI-II) $(p<0.001)$ (TABLE 2) and SASS scores domain 1, 2, 3, $4(\mathrm{p}<0.001)($ TABLE 3). Graphs are shown in fig 1 and 2.

Table 2: Comparison between Pre and Post Depression Scores

\begin{tabular}{|c|c|c|}
\hline \multicolumn{3}{|c|}{ Scores } \\
\hline Barameters & Pre $($ Mean \pm SD) & Post $($ Mean \pm SD $)$ \\
\hline$* \mathrm{p}<0.001$ and $* \mathrm{p}<0.05$ & $32.88 \pm 6.12$ & $16.91 \pm 4.69^{* *}$ \\
\hline
\end{tabular}

Table 3: Comparison between Pre and Post Somatic Symptom Scores

\begin{tabular}{|c|c|c|}
\hline Parameters & Pre $($ Mean \pm SD) & Post(Mean \pm SD) \\
\hline SASS(Pain) & $6.34 \pm 1.50$ & $3.87 \pm 1.55^{* *}$ \\
\hline SASS(Sensory) & $6.75 \pm 2.03$ & $3.92 \pm 2.21^{* *}$ \\
\hline $\begin{array}{c}\text { SASS(Non- } \\
\text { specific) }\end{array}$ & $7.10 \pm 1.86$ & $4.65 \pm 1.57^{* *}$ \\
\hline $\begin{array}{c}\text { SASS(Biological } \\
\text { Function) }\end{array}$ & $6.74 \pm 1.74$ & $4.46 \pm 1.57^{* *}$ \\
\hline
\end{tabular}

$* * \mathrm{p}<0.001$ and $* \mathrm{p}<0.05$ 


\section{International Journal of Science and Research (IJSR) \\ ISSN (Online): 2319-7064}

Index Copernicus Value (2013): 6.14 | Impact Factor (2014): 5.611

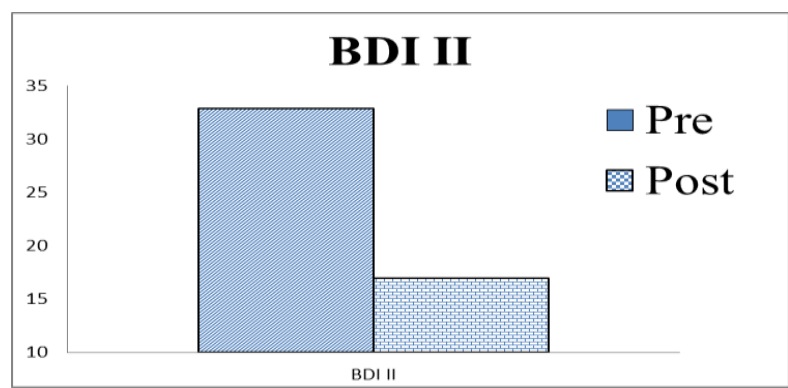

Figure 1: Pre and Post Data for Depression Scores

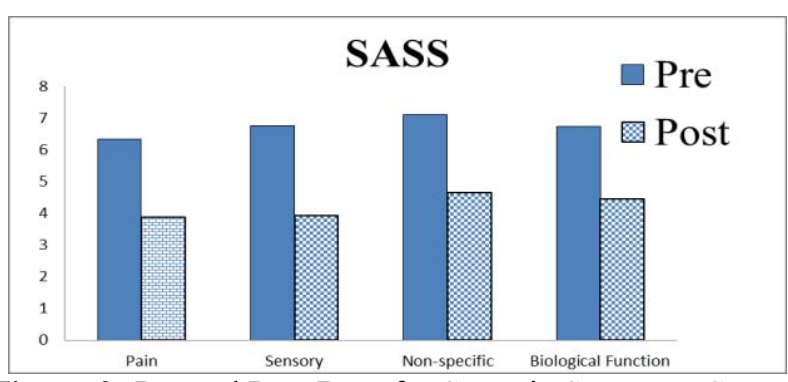

Figure 2: Pre and Post Data for Somatic Symptom Scores

\section{Discussion}

The present study evaluated the effect of Yoga on depression and somatic symptoms and self-esteem of the women labourers. The study has shown that there has been a significant reduction after yoga practice in the depression scores (BDI-II) and somatic symptom (SASS) scores. This study concluded that yoga can help in reducing depression and somatic symptom and increasing self-esteem in the women labour forces.

A study done by Woolery et al, 2004 showed that Subjects who participated in the yoga course demonstrated significant decreases in self-reported symptoms of depression and trait anxiety [10]. Yoga showed greater decreases on the depression score and somatic score compare to control group which received parenting education sessions on the same schedule. Thus, yoga is an effective tool in reducing depression symptoms in women[11]. A study conducted by Bosch [12] showed that yoga decreased in pain and depression scores and improved balance in postmenopausal women after yoga intervention of 3-75 minutes for 10 weeks. A randomized controlled study of Oretzky [13] who assessed Somatic symptoms and sleep quality in young adults who met the criteria for mild depressive symptoms giving intervention of Vinyasa yoga. The results showed after five week intervention significant decreases in somatic symptom scores for yoga, compare to control group.

Yoga classes decreases in self-reported symptoms of depression[14], trait anxiety, levels of negative mood [15] and fatigue following yoga classes[10]. Yoga can improve somatization and mental health status and has implications for the prevention of psychosomatic symptoms in healthy women. [16] The tai chi/yoga reduced depression scores, somatic symptoms, anxiety (STAI) scores and sleep disturbances scores[17] These findings are almost in line with the result of this study.
Yoga has been shown to be an adjunct to assisting the way of women-labourers' lives. Yoga can build up strength to fight their depressions while balancing self-sustainment with continued growth. When they are confident in ones abilities to manage their own thoughts and behaviours, they regain power over their external detrimental factors and their ability to control their own happiness.

\section{Conclusion}

Regular Yoga can be a beneficial, cost effective and selfcorrective practice for labour women's to retain the healthy mental health, further RCT's are required to support. Some of the physiological parameters can be used since in this only psychological parameters were used. The control group engaged in some form of prescribed physical activity to better compare the results.

\section{References}

[1] "Home -Women Labour-About Women Labour:Ministry of Labour and Employment, Government of India," Ministry of Labour and Employment, Government of India, 2015. [Online]. Available: http://labour.nic.in/content/division/women-labour.php. [Accessed: 26-Nov-2015].

[2] C. K.B, "Health Status of Women Labourers in Wakari," IOSR J. Humanit. Soc. Sci., vol. 20, no. 1, pp. 05-09, 2015.

[3] S. Deshpande, H. R. Nagendra, and N. Raghuram, "A randomized control trial of the effect of yoga on Gunas (personality) and Health in normal healthy volunteers.," Int. J. Yoga, vol. 1, pp. 2-10, 2008.

[4] J. Carmody and R. A. Baer, "Relationships between mindfulness practice and levels of mindfulness, medical and psychological symptoms and well-being in a mindfulness-based stress reduction program.," J. Behav. Med., vol. 31, pp. 23-33, 2008.

[5] N. Gupta, S. Khera, R. P. Vempati, R. Sharma, and R. L. Bijlani, "Effect of yoga based lifestyle intervention on state and trait anxiety.," Indian J. Physiol. Pharmacol., vol. 50, no. 1, pp. 41-7, 2006.

[6] T. Descilo, A. Vedamurtachar, P. L. Gerbarg, D. Nagaraja, B. N. Gangadhar, B. Damodaran, B. Adelson, L. H. Braslow, S. Marcus, and R. P. Brown, "Effects of a yoga breath intervention alone and in combination with an exposure therapy for post-traumatic stress disorder and depression in survivors of the 2004 South-East Asia tsunami.," Acta Psychiatr. Scand., vol. 121, pp. 289300, 2010.

[7] A. T. Beck, C. H. Ward, M. Mendelson, J. Mock., and J. Erbaugh, "An inventory for measuring depression.," Arch gen Psychiat, vol. 4, pp. 561-571, 1961.

[8] A. T. Beck, R. A. Steer, and G. K. Brown, "Manual for the Beck depression inventory-II," San Antonio, TX Psychol. Corp., pp. 1-82, 1996.

[9] S. Chaturvedi, A. Michael, and S. Sarmukaddam, "Somatisers in psychiatric care.," Indian J. Psychiatry, vol. 29, pp. 337-42, 1987.

[10] A. Woolery, H. Myers, B. Sternlieb, and L. Zeltzer, “A YOGA INTERVENTION FOR YOUNG ADULTS WITH ELEVATED SYMPTOMS OF DEPRESSION," Altern. Ther. Health Med., vol. 10, no. 2, pp. 60-63, 


\section{International Journal of Science and Research (IJSR) \\ ISSN (Online): 2319-7064}

Index Copernicus Value (2013): 6.14 | Impact Factor (2014): 5.611

2004.

[11]J. Mitchell, "Yoga Reduces Prenatal Depression Symptoms," Psychology, vol. 03, no. 29, pp. 782-786, 2012.

[12]P. R. Bosch, T. Traustadóttir, P. Howard, and K. S. Matt, "Functional and physiological effects of yoga in women with rheumatoid arthritis: a pilot study.," Altern. Ther. Health Med., vol. 15, no. 4, pp. 24-31, Jan. 2009.

[13] S. Oretzky, The Efeect of Yoga on Elavated Depressive and Somatic Symptoms in Young Adults. Alliant International University, San Diago, 2006.

[14] S. Bershadsky, L. Trumpfheller, H. B. Kimble, D. Pipaloff, and I. S. Yim, "The effect of prenatal Hatha yoga on affect, cortisol and depressive symptoms.," Complement. Ther. Clin. Pract., vol. 20, no. 2, pp. 10613, May 2014.

[15] K. Davis, S. H. Goodman, J. Leiferman, M. Taylor, and S. Dimidjian, "A Randomized Controlled Trial of Yoga for Pregnant Women with Symptoms of Depression or Anxiety," Complement. Ther. Clin. Pract., vol. 21, no. 3, pp. 166-72, Jun. 2015.

[16] K. Yoshihara, T. Hiramoto, T. Oka, C. Kubo, and N. Sudo, "Effect of 12 weeks of yoga training on the somatization, psychological symptoms, and stressrelated biomarkers of healthy women.," Biopsychosoc. Med., vol. 8, no. 1, p. 1, Jan. 2014.

[17]T. Field, M. Diego, J. Delgado, and L. Medina, "Tai chi/yoga reduces prenatal depression, anxiety and sleep disturbances.," Complement. Ther. Clin. Pract., vol. 19, pp. 6-10, 2013.

\section{Author Profiles}

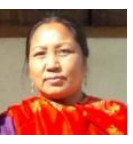

Naorem Shyami Devi finished post graduate diploma in yoga therapy and MSc. Yoga from SVYASA, Bangalore. Working as Yoga Instructor at Swami Vivekananda District yoga and Wellness Center.

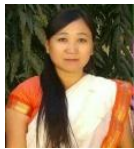

Dr. Naorem Jiteswori Devi received M.A.(Pol. Sc) from Jawaharlal Nehru University, Delhi and $\mathrm{PhD}$. Yoga from SVYASA University, Bangalore. Working as Research officer at Bapu Nature Cure Hospital and Yogashram, Mayur Vihar-1, Delhi.

Dr. Ashween Shashikant Bilagi finished M.D (Yoga and Rehabilitatin) from SVYASA University. Working as Asst. Professor in Svyasa University, Eknath Bhavan, Gavipuram Circle, K G Nagar, Bangalore.-560091 